\title{
Choques morfológicos e crises de sociabilidade no espaço universitário e no espaço urbano
}

\author{
Luiz Augusto Fernandes Rodrigues \\ Universidade Federal Fluminense, Instituto de Artes e Comunicação Social, Departamento de Arte, Rio \\ de Janeiro, RJ, Brasil. E-mail: luizaugustorodrigues@id.uff.br
}

Submetido em 25 de março de 2019. Aceito em 25 de abril de 2019.

\begin{abstract}
Resumo. O presente texto busca discutir algumas permanências do modelo morfológico implantado no Brasil desde um pouco antes da metade do século $X X$ até hoje, argumentando que se privilegiou aspectos formais em detrimento das relações sociais incitadas/permitidas pelos territórios. Retomou-se estudos realizados sobre a produção de espaços universitários, afirmando-se que a produção de determinados espaços urbanos de cidades contemporâneas - em especial aqueles tratados sob a lógica da atratividade turística, mas não somente - reforçam idealizações tão falaciosas quantas as primeiras. Criam-se, assim, morfologias distintas que pouco dialogam: sejam as rupturas observadas nas relações morfológicas entre espaço universitário e espaço urbano circundante, sejam em rupturas no interior do tecido urbano de modo geral. $O$ texto se baseia em argumentações que bucam reforçar qualidades urbanas assentadas nas possibilidades de reforço da sociabilidade, ponderando que tais preceitos são minimizados por lógicas que privilegiam a carga imagética dos espaços em detrimentos de demais valores socioculturais.
\end{abstract}

Palavras-chave. espaço universitário, espaço urbano contemporâneo, sociabilidades, planejamento urbano e cultural.

\section{Introdução}

Meus estudos de doutorado desenvolvidos nos anos 1990 me levaram a concluir/constatar que o modelo urbano e arquitetônico modernista se revelou falacioso, mesmo que tendo se constituído como modelo cristalizado no Brasil (Rodrigues, 2001). Falacioso tanto no sentido de que uma das máximas da arquitetura modernista "a forma segue a função " se mostrou muito mais uma retórica discursiva do que um parâmetro norteador de muitas morfologias urbanas e tipologias arquitetônicas, podendo-se argumentar que mesmo sob tal "máxima", se produziu campus e cidades universitárias povoadas de edifícios-ícones muitas vezes com graves deficiências de utilização (como questões sonoras e ambientais do Instituto Central de Ciências [ICC] da Universidade de Brasília [UnB], projetado por Oscar Niemeyer, entre outros exemplos), assim como a preconização de se ter o espaço universitário como um dos setores conformadores da planejada cidade moderna (conforme preceituada pela Carta de Atenas, de 1933) promoveu, em muitos casos, uma ruptura desastrosa e elitizada entre cidade e universidade.

Em complemento a isso, os ideários do planejamento estratégico contemporâneo da virada do século XX para o XXI, ao invés de se afastar de soluções que já vinham se mostrando desagregadoras, vão na direção de acirrar determinadas características setorizantes e excludentes (mesmo que travestidas de inclusivas e diversificadas) que privilegiam as relações econômicas em detrimento das relações socais, produzindo espaços de forte atratividade turística e de investimentos de capitais internacionais globais, mas que não potencializam relações de sociabilidade e de apropriação espacial mais efetiva. Pode-se observar tais resultados tanto nos estudos que desenvolvi sobre as soluções urbanas implementadas na cidade 
de Niterói/RJ, a partir de projetos arquitetônicos de Oscar Niemeyer (Rodrigues, 2015a; 2015b), assim como diversos estudos sobre regeneração de áreas portuárias pelo mundo afora, como no caso da região do Porto Maravilha (Rio de Janeiro/RJ) que apontam o mesmo tipo de solução: espaços de forte atratividade turística e de consumo estruturados a partir de soluções arquitetônicas emblemáticas "assinadas" pelos mais reconhecidos arquitetos internacionais.

Acrescente-se, ainda, que se percebe inclusive soluções arquitetônicas contemporânas falaciosas, conforme comentado anteriormente em relação ao campus universitário; "a forma segue a função" parece nem sempre vigir mesmo hoje em dia, podendo-se ilustrar com projeto do próprio arquiteto Oscar Niemeyer: o projeto do Teatro Popular Oscar Niemeyer apresenta uma parede lateral toda em vidro, o que o torna inadequado à função teatral quando se considera a entrada de luminosidade, tanto de dia quanto à noite. Também em relação às morfologias urbanas percebe-se muito mais permanências do que rupturas quando se observa o modelo norteador de meados do século passado e o modelo atual, mesmo após toda as críticas tecidas em relação ao modelo urbano modernista: setores inteiros de muitas de nossas cidades ainda são pensados/planejados desconsiderando a necessária diversidade funcional dos espaços (cf. Jacobs, 1977, entre outros). Como exemplo podemos citar o Caminho Niemeyer em Niterói/RJ (que será melhor explorado ao longo deste artigo) que apresenta uma grande área formada por apenas edifícios com uso cultural, caracterizando-se como um local pouco frequentado (à exceção de momentos de fluxo de turistas ou de grandes eventos) por conta de sua monofuncionalidade (a apropriação desse local por jovens em busca de utilizar suas superfícies lisas para prática de alguns esportes é reiteradamente "negada", como será mais detalhadamente explorado).

Se o campus moderno/modernista se mostrou um modelo falacioso uniforme/uniformizador, o modelo urbano atual se mostra regido por lógica similar.

Ressalte-se, aqui, breves referências empíricas: o modelo urbano implantado nos espaços físicos da maioria das universidades brasileiras se mostrou tão cristalizado que algumas tentativas de ruptura se revelaram inócuas. A excessiva setorização do espaço universitário no interior de tecidos urbanos, o islomento espacial e ruptura morfológica (modelo modernista intra-campus versus soluções mais vernaculares extra-muros) embora tenham gerado soluções guetificadas, se mostraram tão enraizadas e cristalizadas que inviabilizaram propostas diferenciadas desse modelo. Exemplos são muitos, mas destacamos aqui três momentos conjunturais: a implantação da Cidade Universitária da Universidade do Brasil a partir do final dos anos de 1930; a construção do Campus Universitário da Universidade de Brasília no início dos anos 1960; a tentativa derrotada de implantar a área de ciências humanas da Universidade Federal do Maranhão em parte do Centro Histórico de São Luís.

Soluções urbanas mais contemporâneas vêm produzindo espaços de forte atratividade turística assentada em valores icônicoimagéticos, mas nem sempre acompanhados de soluções que potencializem suas dimensões sócio-relacionais; voltaremos e exemplificaremos tal assertiva mais à frente.

Este texto busca reforçar a necessidade de soluções urbanas capazes de se contrapor a essa lógica, se configurando como alternativas que possam justificar a expressão de Walter Benjamin (2012, p. 245) ao propor "escovar a história a contrapêlo". Busca-se refletir sobre a produção do espaço e as práticas socioculturais resultantes e vislumbrar/flagrar formas de produção de espaço que tragam reforço à sociabilidade.

\section{Resistências e cristalização do moderno na arquitetura brasileira}

O Rio de Janeiro do século XIX nos lembra a cidade grega. Não que o tivéssemos dividido em uma área sagrada, e outra residencial e pública; em certos casos, até tínhamos os mosteiros e igrejas coloniais assentados nos principais morros centrais. Não é a isso que pretendo me ater, mas sim olhar a realidade habitacional daquele momento - o século XIX -, onde elites ricas e população pobre conviviam lado a lado, tendo como diferenciação entre eles forma e tamanho de suas residências e não locais propriamente separados conforme a condição econômica, tal qual a cidade da antiguidade grega. 
Essa convivência espacial de classes diferentes acirra-se tanto com a vinda da corte portuguesa para o Brasil (aumentando quantitativamente a elite, aristocrática), quanto com a ascensão da economia cafeeira e a independência política (aumentando quantitativamente a elite, urbana e capitalista), momento em que o centro da cidade passa a acolher, cada vez mais, escravos livres e homens pobres dedicados aos serviços urbanos. São duas ordens econômicas que se sobrepõem - escravista e capitalista - e duas classes distintas que se avizinham.

A partir de fins do século XIX, os novos meios de transporte implantados na antiga cidade colonial - bonde a burro e trem a vapor - vão permitir que tais classes tão díspares tomem direções opostas, uma rumo ao sul, outra rumo ao norte. Coube, principalmente, à área central, ainda manter usos comuns para classes diferentes, porém não por muito tempo, pois as reformas urbanas do início do século XX vão tratar de pôr "ordem" ao espaço urbano central carioca.

Com justificativas que vão desde melhores condições de higiene esaúde pública até o embelezamento e ordenamento necessários para pôr a capital da República no rol das "modernas" cidades do mundo, inicia-se, deforma mais explícita, o processo de apartamento das distintas classes sociais da cidade.

Não pretendo alongar-me nesse período - já tão trabalhado sob infindos enfoques -, e sim, apenas, ilustrar esquematicamente os primeiros momentos de guetificação, daquela que se tornaria a primeira cidade brasileira a entrar nos rumos da modernização urbana.

A velha cidade colonial, de feições medievais (ruas estreitas, densos casarios mesclando moradia e trabalho, ocupações estratégicas dos morros) cedia lugar a um ideal novo: modernas áreas portuárias, modernos meios de transporte - o bonde elétrico e o automóvel -, modernos edifícios-símbolos da nova ordem capitalista, cafeicultora e imobiliária. Enquanto estilo arquitetônico, vivia-se, ainda, sob o signo de um ecletismo de cunho classicista, ou mesmo neocolonial. A forma urbana modernista virá somente depois.

É nos anos 1930 que as correntes arquitetônicas modernistas vão ter eco no Brasil. O país em construção durante o Governo Vargas é o país em fase de modernização: política, industrial, financeira e espacial.

O Brasil já vinha despontando, nos primeiros anos do século, no campo literário e artístico modernista. Só para lembrar: o manifesto futurista divulgado por Oswald de Andrade em 1912; as exposições de arte moderna de Anita Malfati (em 1917, em São Paulo) e de Di Cavalcanti (em 1921, no Rio de Janeiro); a Semana de Arte Moderna em 1922; a publicação de Macunaíma de Mário de Andrade em 1928. Em termos de arquitetura, era o neocolonial que ganhava adeptos e que marcava um movimento de renovação de cunho nacionalista. Chamando a si, também, o cunho nacionalista, o modernismo tenta impor-se como "arte nacional sem nacionalismos", conforme palavras de Di Cavalcanti. Le Corbusier foi o paradigma dessa vertente arquitetônica moderna.

Pesquisei, ao longo da década de 1990, morfologias do espaço universitário. Peguemos como ilustração o projeto da Cidade Universitária da Universidade do Brasil. Embora tenha havido todo um empenho por parte do Governo Federal, representado aqui na figura do Ministro Gustavo Capanema, foram difíceis os caminhos desse projeto modernista. As tendências eram várias e as opiniões da intelectualidade e dos técnicos da época divergiam em muitos pontos. As propostas da equipe italiana Piacentini-Mopurgo, volta e meia, eram retomadas. As ideias formuladas por Le Corbusier, embora tenham influído no projeto finalmente levado a cabo, não f oram aceitas totalmente. Enfim, o projeto que visava dar forma nova à materialização arquitetônica-urbanística no Brasil da maneira mais abrangente, e com o respaldo do Governo Federal, não foi hegemônico naquele momento, haja vista a longa demora e as alterações a que foi submetido o projeto urbanístico daquela universidade.

Se a construção do MES - Ministério de Educação e Saúde ${ }^{1}$ - já dera alguns louros ao governo varguista ${ }^{2}$, como promotor da nova arquitetura moderna, a construção da Cidade Universitária ratificaria e assentaria, definitivamente, tal posição. Os caminhos, no entanto, esbarraram em resistências. No final, vence o projeto modernista de inspiração corbusiana. Mais do que isso, aos poucos vai despontando e marcando definitivamente o seu lugar, a moderna arquitetura brasileira. "O Pavilhão Brasileiro na Feira Mundial de 
Nova York, em 1939-40, consagrou definitivamente Lúcio Costa e Oscar Niemeyer", como nos afirma o professor Carlos Lemos (1979), abrindo o caminho que os colocaria na posição de emblemas nacionais de nossa arquitetura.

Estabeleci, a partir de minhas pesquisas de pós-graduação, três diferentes fases da implantação do modernismo arquitetônico no Brasil: a construção do signo modernista (e as resistências inerentes à construção de um novo signo, de uma nova ordem estético-cultural); a naturalização desse signo, a sua incorporação definitiva; e, uma vez perfeitamente incorporado, a idealização que fez dele um signo estanque (e as resistências domoderno a mudanças, a alterações em seu significante). Tal periodização tem rebatimentos claros quando se observa o espaço universitário brasileiro:

- $1^{\mathrm{a}}$ fase (1930/1960) - caracterizada pelas propostas de Cidades Universitárias, seguidoras de uma ótica funcional conforme retratada na Carta de Atenas (1933). Pela Figura 1, observa-se: a) a setorização prevista para o Plano Diretor da Universidade Federal do Rio de Janeiro/UFRJ; b) a separação formal entre espaço urbano e espaço universitário, unidos por duas pontes, assim como a morfologia interna do campus que, através de grandes quadras e separação de acessos motorizado e peatonal, corrobora a ruptura com a morfologia mais vernacular que estrutura o tecido urbano (aqui não representado).

- $2^{\mathrm{a}}$ fase (nos 20 anos seguintes) caracterizada pelos modelos de Campi Universitários, definidos segundo uma ótica muito próxima à anterior, e diferenciando-se daquela, principalmente, em relação ao tratamento dos edifícios. Pela Figura 2, observam-se o zoneamento setorizado e a separação dos meios de acesso - motorizado e peatonal - tal como observado na Figura 1 .

- $3^{\mathrm{a}}$ fase (pós-1980) - caracterizada pela manutenção do modelo anterior, embora este apresente claros sinais de esgotamento e muitas críticas. Vê-se surgirem propostas de revisão do modelo, que praticamente não saem do papel, ou são inexplicitamente rejeitadas. Importante exemplo foi o que aconteceu com a Universidade Federal do Maranhão. No início dos anos 1980, técnicos do MEC (Ministério da Educação e Cultura) conseguiram convencer o BID (Banco Interamericano de Desenvolvimento) quanto à aplicação dos recursos financeiros contratados junto ao Acordo MEC-BID III na consolidação de ao menos parte da área física daquela universidade no Centro Histórico (no caso, a área de ciências humanas, que não demandaria instalações e laboratórios mais complexos e diferenciados). Convence-se $o$ agente financiador, mas a proposta foi rejeitada pela comunidade universitária. A Figura 3 nos apresenta a proposta do MEC de utilização de quadras no Centro Histórico.

Esta periodização pode ser associada às reflexões em formulação: a) uma $1^{\text {a }}$ fase, caracterizada pela resistência ao modernismo, e que seria o momento dos esforços para sua implementação; b) uma $2^{\mathrm{a}}$ fase, na qual o projeto de modernidade da arquitetura brasileira já se encontra definitivamente assentado; c) uma $3^{\text {a }}$ fase, desdobramento da anterior, na qual se vê uma pregnância tão acirrada do modelo, que inviabiliza qualquer proposta de ruptura, na qual o que se constata é a resistência do moderno. Uma idealização da modernidade, tida então como modelo único, não pluralizado, cristalizado.

Tecidas, anteriormente, algumas das forças que compuseram a $1^{\text {a }}$ fase, vejamos, então, certas forças que compõem as demais.

O modelo urbano modernista, proposto ao longo da década de 1930, encontrou eco nas propostas de algumas das maiores universidades brasileiras: a UB (hoje UFRJ), a USP, a UFMG ${ }^{3}$, principalmente. Encontrou ressonância, também, em várias propostas de renovação e/ou ampliação urbana, podendo-se destacar o projeto do bairro da Pampulha em Belo Horizonte como o de maior relevância, e aquele que poria Oscar Niemeyer como o emblema, não só de nossa arquitetura oficial, mas, 
efetivamente, como o emblema da arquitetura brasileira.

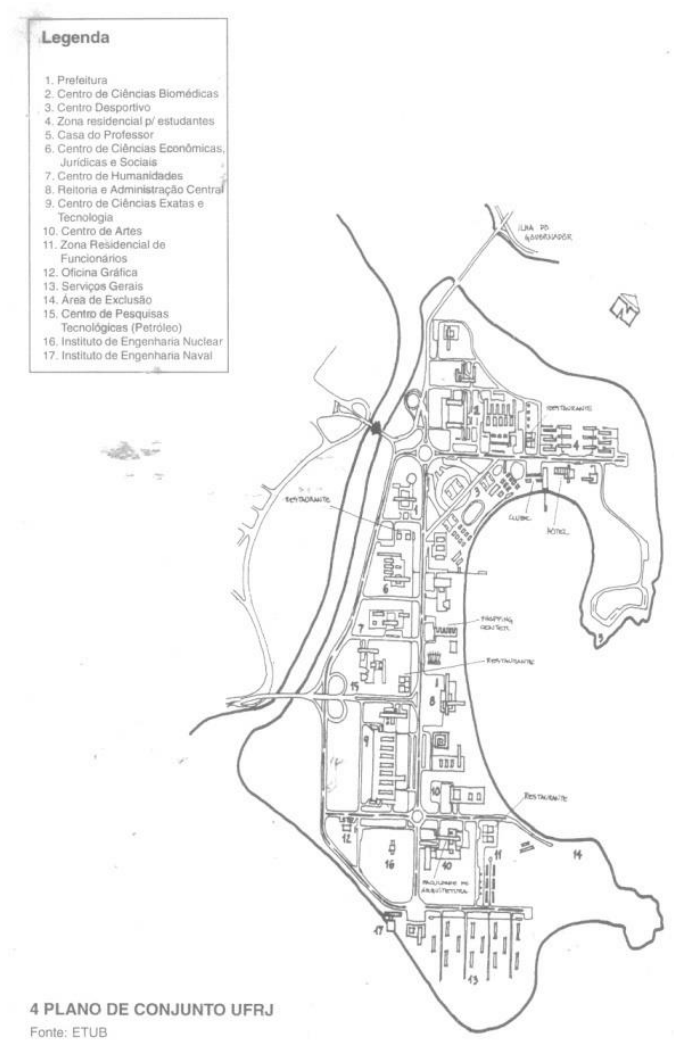

Figura 1. Plano físico da Universidade Federal do Rio de Janeiro (UFRJ), conforme acervo do Escritório Técnico da Universidade do Brasil (ETUB) (fonte: ETUB apud Rodrigues, 2001, p. 98)

Quando a II Guerra Mundial acabou, a arquitetura brasileira já tinha cruzado fronteiras. Em 1942 o Museu de Arte Moderna de Nova York fizera uma exposição sobre nossa arquitetura, confrontando o tradicional e o moderno, da qual resultou a publicação Brazil Builds, com 40 projetos modernistas.

Não existiam mais motivos para se buscar técnicos estrangeiros, tínhamos os melhores. Niemeyer projetou a Pampulha (1939-1941) e, junto com Lúcio Costa, Brasília (1957-1961). Se Getúlio Vargas e Gustavo Capanema haviam sido os mecenas da primeira fase, Juscelino Kubitschek foi o da segunda enquantoPrefeito de Belo Horizontee depois Presidente do Brasil. O Rio de Janeiro a capital-ícone da primeira fase;Brasília a capital-ícone da segunda. Como asseverou Carlos Nelson dos Santos (1988, p. 43-44):
Construída Brasília, falácia democrática oferecida ao consumo da parcela mínima da população brasileira que podia assumir a 'cidadania' proposta pelo PlanoPiloto, dedica-se, nos anos 60, a oferecer os mesmos esquemas racionalistas para os de mais baixa renda. [O Governo] Financia, através do BNH, os Conjuntos Habitacionais.

$[\ldots]$

As cidades teriam de se configurar pelo código racionalista porque todos os brasileiros, não importando as enormes diferenças interclasses, teriam em comum uma só razão.

Ao modelo morfológico de Brasília, baseado na rígida separaçãodos espaços por funções específicas (o que é, na verdade, ainda um reflexo daCarta de Atenas com suas funções urbanas: morar, trabalhar, circular, sedivertir), juntou-se o modelo educacional universitário proclamado por certossetores da sociedade, e posto em prática a partir da criação da UnB/Universidade de Brasília. O ensino separado em setores (departamentos) permitia que o espaço se moldassesegundo a mesma lógica. Os campi universitários serviriam, então, como palco de realizações urbanas racionalistas/modernistas.

Assistiu-se, nas décadas que seguiram a criação da UnB, a soluções reflexas desta, fosse no norte ou no sul, fosse em universidades públicas ou privadas, leigas ou confessionais.

As críticas ao modernismo pouco conseguiam atingir a produção arquitetônica brasileira. Estávamos imbuídos da certeza do modelo certo, afinal, fora ele que melhor divulgara o País. Sua grandiosidade era possível e desejável a um Brasil-grandepotência e país do milagre econômico máximas da conjuntura da ditadura militar vigente no País de 1964 a 1985. As grandes somas em empréstimos mundiais contratados junto ao BID/Banco Interamericano de Desenvolvimento, mais do que melhorar a qualidade do ensino e da aprendizagem nas universidades, serviam para dotar-lhes de modernos espaços físicos. 


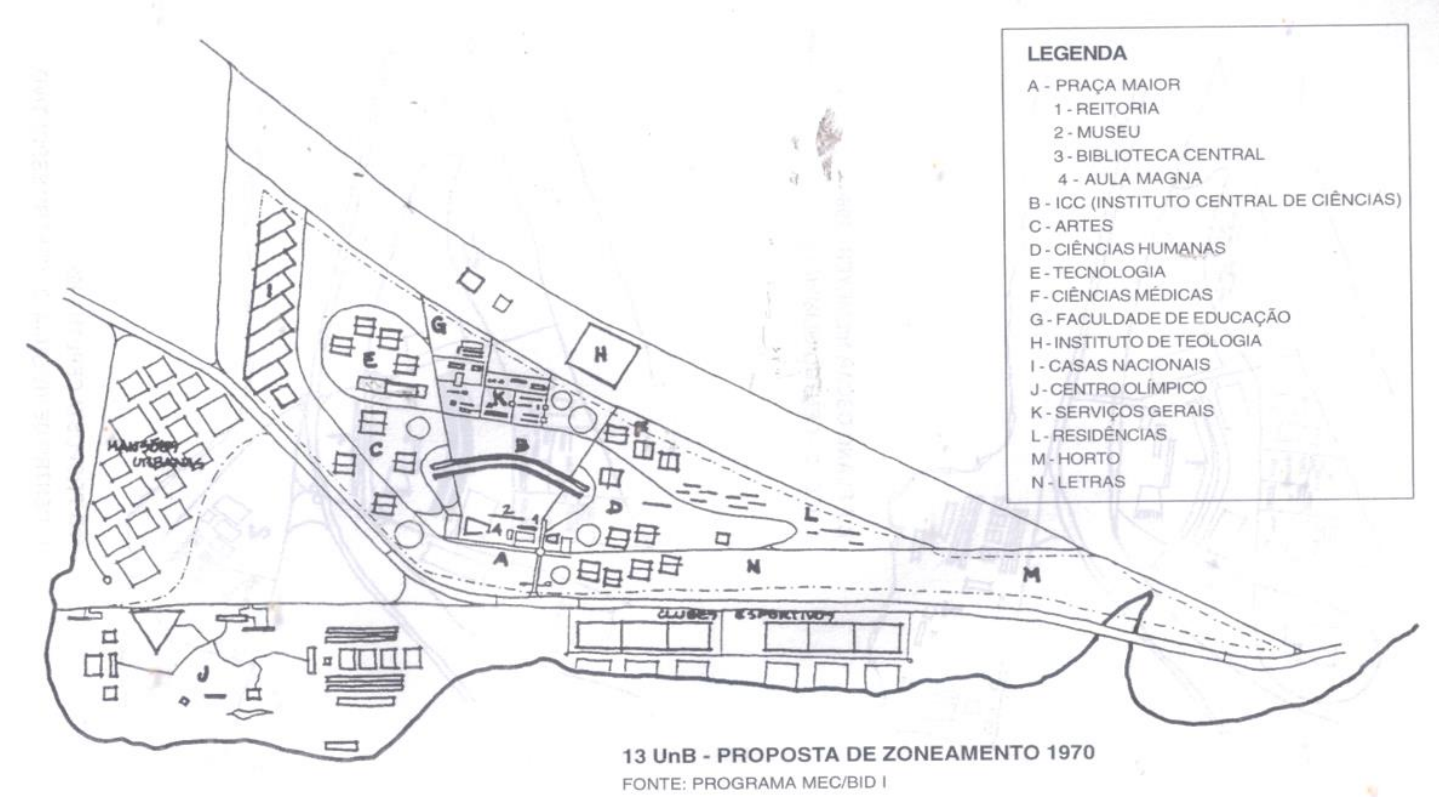

Figura 2. Plano físico da Universidade de Brasília (UnB), conforme proposta de zoneamento constante dos documentos do Acordo entre o Ministério da Educação e Cultura (MEC) e o Banco Interamericano de Desenvolvimento (BID) (fonte: Programa MEC/BID I apud Rodrigues, 2001, p. 134).

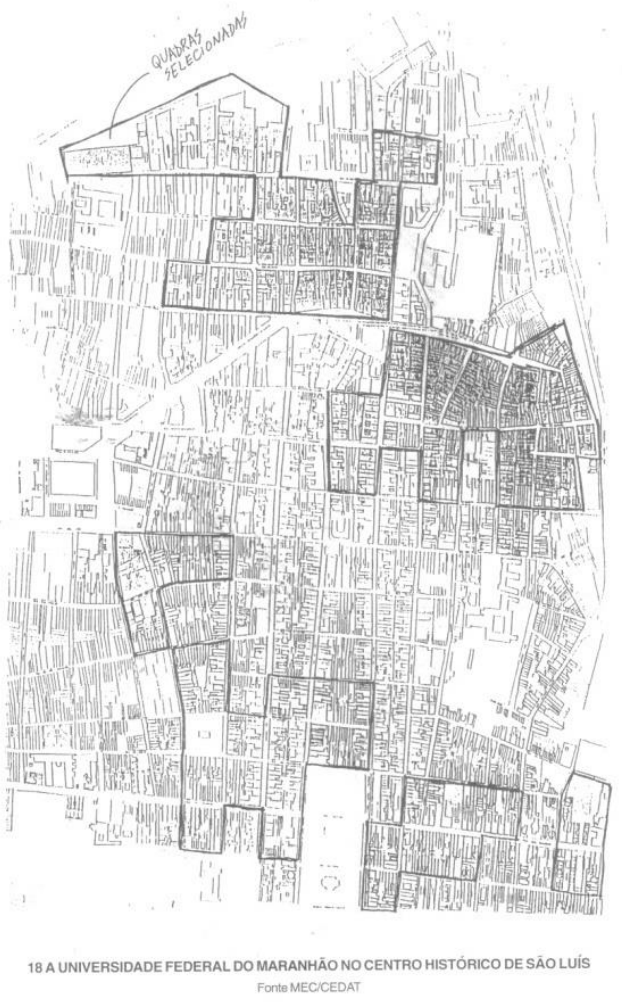

Figura 3. Proposta de implantação de parte do campus da Universidade Federal do Maranhão no Centro Histórico de São Luís, conforme acervo do Centro de Desenvolvimento e Apoio Técnico à Educação (CEDATE) do Ministério da Educação e Cultura (MEC) (fonte: MEC/CEDATE apud Rodrigues, 2001, p. 186)
Nem a "crise do milagre", a revogação do AI-5, ou o início de uma "abertura política" conseguiram favorecer novos olhares sobre o planejamento urbano segregador. $\mathrm{O}$ descrédito da velha fórmula (planejamentos desenvolvimentistas; planos diretores centrados em longos levantamentos quantitativos; conjuntos habitacionais segregados e monótonos) não resultou na busca de outras possibilidades. As propostas novas acabavam recaindo na velha solução. A construção do signo modernista único mostrava-se ainda forte.

É de novo Santos quem argumenta:

Se algo deve ser destacado nas tipologias urbanas brasileiras é sua insistência em soluções emblemáticas. Háquase cem anos, Estado e sociedade investem, de comum acordo, em um futuro que pode ser apressado através da construção de novas cidades. A cidade, símbolo econsequência do progresso, é usada como sinédoque. (Santos, 1988, p. 65)

Em relação ao espaço universitário, os anos 1980 viram surgir propostas que apontavam rupturas com o modelo vigente. Pode-se citar o projeto de adensamento da Universidade Federal de Goiás na Praça Universitária (Centro de Goiânia), o projeto para a 
Universidade Federal do Maranhão no Centro Histórico de São Luís, o projeto de eixos de integração para o Campus da UnB. Todos projetos "derrotados"!

Somando-se à uniformização do modelo físico, pode-se acrescentar que a setorização espacial criada resultou em certa guetificação do espaço, seja em relação aos diálogos universidade/cidade, seja quanto às relações sociais geradas intra-campus universitário. Edifícios-ícones e campi segregados se mostram tão inibidores e reificadores quanto imagens-símbolos produzidas contemporaneamente em muitas de nossas cidades, como exemplificam o Museu do Amanhã na área portuária da cidade do Rio de Janeiro, e o Museu de Arte Contemporânea na cidade de Niterói.

Acredita-se que as cristalizações observadas em relação ao espaço universitário acontecem de maneira similar quando enfocamos outros espaços da cidade, em especial produções mais contemporâneas, assentadas na atratividade turística e de capitais internacionais, como abordaremos e ilustraremos mais ao final do artigo.

\section{Aproximações metodológicas}

Precisamos, urgentemente, desenvolver metodologias que nos ajudem a identificar potências (e mesmo inibições) nos modos possíveis (e mesmo permitidos) de efetiva apropriação dos espaços com reforço das sociabilidades. Venho apostando na utilização de métodos que mesclem a dimensão urbana e a dimensão cultural, em especial duas estratégias metodológicas de discussão mais contemporânea: o Cultural Mapping e o Multicultural Planning; ambas apoiadas no conceito de diversidade cultural - cada vez mais presente nas realidades urbanas em geral.

O Cultural Mapping é uma ferramenta que busca auxiliar o planejamento urbano combinando recursos culturais, sociais, territoriais etc. Como apontam Duxbury, Garret-Petts e MacLennan (2015, p. 22, tradução minha):

cultural mapping é considerado como uma ferramenta sistemática para envolver as comunidades na identificação e registro dos bens culturais locais, com a implicação de que esse conhecimento será então usado para informar estratégias coletivas, planejamento de processos, ou outras iniciativas. Estes bens são tangíveis, ou quantitativos (por exemplo, espaços físicos, as organizações culturais, formas públicas de promoção e auto representação, arte pública, indústrias culturais, patrimônio natural e cultural, arquitetura, pessoas, artefatos e outros recursos materiais) e intangiveis, ou qualitativa (por exemplo, valores e normas, crenças e filosofias, linguagem, narrativas da comunidade, histórias e memórias, relações, rituais, tradições, identidades e sentimento comum de lugar). Juntos, esses bens ajudam a definir as comunidades (e ajudam as comunidades a se definirem) em termos de identidade cultural, vitalidade, senso de lugar e a qualidade de vida.

Defendemos que se fortaleçam ações e pesquisas que se apoiem na possibilidade de se estudar mecanismos de maior integração entre ações governamentais e formas de participação social, entendendo-os como subsídios para melhores soluções para as cidades, assim como para a produção/ampliação de novos e maiores repertórios que suportem nossas práticas culturais.

Considera-se que as metodologias apontadas trazem expressivos aportes de experiências no campo do planejamento (tanto urbano quanto cultural) ao se afastar de perspectivas somente econômicas e administrativas na direção de possibilidades identitárias, cidadãs e participativas que se apoiam na ideia de diversidade cultural com reforço das diferenças e maiores possibilidades de inclusão social, e que se configuram como importantes ferramentas do chamado Multicultural Planning - que pretende ouvir as vozes esquecidas, superando o risco de ignorar as diferenças e, desse modo, se opondo ao caráter pretensamente universal (e uniformizador) das práticas de planejamento.

Mohammad Abdul Qadeer e Sandeep Kuman Agrawal (2011, p. 132, tradução minha) assim argumentam sobre o Multicultural Planning:

Usando a noção de políticas muticulturais como base para a 
formulação de um questionário, vamos examinar os departamentos de planejamento urbano das regiões metropolitanas com uma alta taxa de imigrantes nos Estados Unidos e no Canadá. Passar em revista a noção de políticas multiculturais, apesar de condições limitadas, revela diferenças interessantes na prática do planejamento urbano. [...] Tal prática vai para além do quadro teórico, $e$ preconiza principalmente maior sensibilidade para as diferenças culturais e uma ênfase sobre a participação das minorias étnicas

Ainda seguindo propostas do Multicultural Planning, Leonie Sandercock (2005) aponta a necessidade de captura de discursos diversos sobre as experiências vividas nas cidades e cujas histórias precisam ser "resgatadas" (e propõe a sua gravação em vídeo como metodologia de trabalho) e que devem se transformar em estratégias para o planejamento. Eis como a autora argumenta sobre o uso das histórias no planejamento: "Foi o processo de narração de histórias que levou as pessoas a superar 'as minhas necessidades versus as suas necessidades' para chegar a um 'plano mais elevado' em direção a algum objetivo comum" (p. 295). A autora destaca que "nos contextos multiculturais, geralmente há uma cultura dominante cuja versão de eventos, de comportamento e de práticas constitui a norma implícita" (p. 300). Sandercock (2005, p. 292) propõe como metodologia a gravação em vídeo argumentando que:

\section{Primeiro, há uma estrutura temporal ou sequencial, que muitas vezes envolve o tique-taque de um relógio para criar tensão dramática. Segundo, há um elemento de explicação ou coerência, em vez de uma enumeração de uma coisa depois da outra. \\ Terceiro, há algum potencial para generalização, para ver o universal no específico, o mundo em um grão de areia. Quarto, há a presença de convenções genéricas e reconhecidas que se relacionam com uma estrutura esperada, uma estrutura de enredo e protagonistas.}

Acreditamos que flagrar percepções e formas de recepção do espaço contribui de forma decisiva para melhor produzir territorialidades que se rebatam nos valores culturais dos usuários, e com isso reforcem práticas e relações de sociabilidade.

\section{Fundamentos}

A cidade nos tempos atuais vive um grande impasse, considerando que os espaços coletivos estão perdendo seu uso de forma crescente e a princípio por questões diversas: 1. pela questão da segurança, pois se tem medo de ficar em espaços livres de forma desinteressada; 2. pela questão ideológica, que demanda o uso de espaços mais privatizados como praças de shoppings e espaços mais fechados e restritos; 3 . pela questão do modelo urbanístico, uma vez que os espaços são valorizados mais por sua carga imagética do que relacional, ou seja, espaços esteticamente valorizados, mesmo que com pouco uso (verdadeira falácia; uma "permanência" do modelo arquitetônicourbanístico moderno que se estrutura muito mais a partir da solução icônico-imagética do que das soluções relacionais entre forma arquitetônica e vida urbana). Ou seja, cidades pensadas como cenários; então proponho tensionar o espetáculo que vem sendo a cidade.

Atualmente, venho pesquisando algumas relações entre práticas de planejamento urbano e práticas culturais lato sensu, em especial observando o esvaziamento de uso em espaços públicos; ou mesmo usos intensos, mas "esvaziados" de sociabilidade.

Em meus estudos de doutorado (meados dos anos 1990), analisei aspectos morfológicos do espaço universitário (e as concepções arquitetônicas e político-ideológicas que lhes deram suporte). Me ocupei, naquele momento, em perceber como o projeto modernista que deu base ao projeto morfológico universitário (em especial no Brasil) se tornou modelo vitorioso e hegemônico, e como tal modelo inibe/impede relações sociais mais plenas. Embora eu tenha desviado meu objeto de pesquisa do espaço universitário para o espaço urbano em si, venho buscando retomar o objeto inicial.

Meu objetivo é dar prosseguimento às minhas reflexões atuais, ou seja, buscar compreender aspectos culturais e de sociabilidade presentes na cidade contemporânea (ainda impactados pelas críticas dos situacionistas e dos críticos à dita arquitetura neomoderna), mas fazendo o 
devido cruzamento com a temática de meus estudos anteriores (ou seja, os espaços universitários e a separação entre espaço universitário e a cidade como um todo).

Tais análises, acredito, em muito podem contribuir com críticas às soluções que hoje são pensadas para as cidades contemporâneas, especialmente a partir de grandes projetos de cunho turístico e cultural. Venho buscando refletir sobre políticas culturais para os territórios assim como políticas urbanas que fomentem práticas culturais, construídas com participação comunitária. Política concebida como exercício de nossos direitos e disputa por nossas concepções de mundo e de vida. Por mais que as políticas tendam a ser entendidas como ações governamentais, é bom reforçar que todos nós podemos construir políticas a partir de nossas ações coletivas.

Meu foco são políticas culturais e políticas para os territórios. Comecemos pelas políticas culturais e trazendo o entendimento de Néstor García Canclini (1990, p. 26, traduição minha), que a define como o

conjunto de intervencões realizadas pelo Estado, por instituições civis e por grupos comunitários organizados afim de orientar o desenvolvimento simbólico, satisfazer as necessidades culturais da população e obter consenso para um tipo de ordem ou de transformacão social.

Os exemplos que se pode apontar são vários, mas atento-me ao caso da região oceânica do município de Niterói/RJ. A região não conta com nenhum equipamento cultural público (e mesmo quase nenhum equipamento cultural, à exceção de alguns ateliês de artistas visuais). O projeto Ponto de Cultura Niterói Oceânico - por mim coordenado a partir de edital do Ministério da Cultura, de 2006 a 2012 - passou a representar um importante lócus de construção de política, tanto para alavancar ações no âmbito da cultura quanto na produção de um território de sociabilidades, e mesmo criar condições iniciais para diversos jovens assumirem autonomia em suas ações políticas, e satisfação de algumas de suas necessidades culturais (assim como a criação de outras tantas demandas de acesso a outros repertórios e práticas culturais e artísticas), corroborando o apontado por Canclini.
Outro exemplo de construção de políticas culturais para o território a partir de grupos sociais pode ser observado na prática corrente das Rodas Culturais que vêm ocupando diversas praças de várias cidades com atividades ligadas à cultura hiphop, como as Batalhas de Rima entre outras expressões. Esta questão será retomada mais adiante.

Os exemplos são vários, mas ficamos por aqui com apenas uma ilustração do que queremos defender como construção de políticas culturais para além das gestões públicas governamentais, numa espécie de duplo exercício em que os cidadãos também constroem políticas e ressignificam processos.

\section{Direito à cultura}

Começo fazendo eco às palavras de Alexandre Barbalho (2009, p. 2-3, tradução minha da citação de Bolán) quando aponta que

política cultural (cultural policy) diz respeito ao universo das políticas públicas voltadas para a cultura implementadas por um Governo. Em outras palavras: "um processo no qual o Estado impõe um tratamento político - isto é, resultado do debate público sobre o sentido da ação do Estado àquilo que chama cultura" e cujos objetivos consistem em "ordenar, hierarquizar ou integrar um conjunto necessariamente heterogêneo de atores, discursos, pressupostos e práticas administrativas" (Bolán, 2006, p.60). Já as políticas de cultura (cultural politics) se referem às disputas de poder em torno dos valores culturais ou simbólicos que acontecem entre os mais diversos estratos e classes que constituem a sociedade. Apoiando-se em Jim McGuigan (1996), podemos afirmar que elas dão conta do confronto de idéias, das disputas institucionais e das relações de poder na produção, circulação/distribuição e recepção/consumo de bens e significados simbólicos. Deve-se entender que as dimensões da cultural policy e da cultural politics não são independentes, muito pelo contrário, são interdependentes, já que as ações 
e disputas de uma alimentam a outra e vice-versa (Ortiz, 2008).

Estou aqui buscando reforçar a ideia de que as políticas culturais são e precisam ser pensadas a partir da noção de compartilhamento de sua construção e gestão; e aqui não estou nem minimamente me referindo a certos entendimentos de gestão pelo viés empresarial ou empreendedorista. Gestão de políticas culturais é aqui entendido com seu acento da palavra cultura e não na palavra gestão (perspectiva já trabalhada nos textos (Rodrigues, 2009; 2012 e Rodrigues \& Correia, 2017).

Além de buscar fortalecer e reafirmar a noção de política e de gestão cultural a partir do viés do compartilhamento de suas construções, reforço aqui duas outras ideias a embasá-las. Primeiro a questão acionada por Nancy Fraser ao chamar atenção para o fato de que as lutas por reconhecimento identitário dos diversos e diferentes modos culturais não devem ser concebidas sem a necessária luta por redistribuição de renda e construção de condições econômicas mais igualitárias. As premissas do reconhecimento multicultural não são plenas sem justiça social:

A "luta por reconhecimento" está rapidamente se tornando a forma paradigmática de conflito político no final do século XX. Demandas por "reconhecimento da diferença" dão combustivel às lutas de grupos mobilizados sob as bandeiras da nacionalidade, etnicidade, "raça", gênero e sexualidade. Nestes conflitos "pós-socialistas", a identidade de grupo suplanta o interesse de classe como o meio principal da mobilização política. A dominação cultural suplanta a exploração como a injustiça fundamental. E $O$ reconhecimento cultural toma o lugar da redistribuição socioeconômica como remédio para a injustiça e objetivo da luta política. (Fraser, 2006, p. 231)

Acrescentem-se, também, a concepção sobre desculturalizar a cultura apontada nas palavras de Victor Vich (2015, p. 20):

A proposta de desculturalizar a cultura implica então em arrancar a cultura de sua suposta autonomia e utilizá-la como recurso para intervir na transformação social. As políticas culturais atuais devem posicionar-se, acima de tudo, como agentes críticos da modernidade que Walter Benjamin figurou como um pavio aceso. Em sua opinião o progresso, liderado somente por uma pura acumulação do capital, não se dirige ao desenvolvimento, mas à destruição do mundo. Benjamim sustentava: "É preciso cortar o pavio ardente antes que a chama alcance $o$ dinamite" ([1955] 1987, p. 64).

Quero, com isso, reforçar que o campo das políticas culturais deve criar condições de expressão para todos os sujeitos sociais em seus mais diversos universos simbólicos, satisfazendo e ampliando repertórios estéticos e relacionais, e reforçando condições de coesão social. Ainda tem se mostrado necessário retirar a compreensão sobre cultura de sua suposta ligação a determinados padrões e valores estéticos (muito redutores) e/ou apenas à valorização de determinadas práticas e concepções de mundo (também - tendencialmente - muito redutores); é preciso desculturalizar a noção de cultura para que as políticas de cultura sejam mais amplas, inclusivas, integradas, estruturantes, instituintes, enfim políticas culturais que reforcem também universos éticos ampliados, e se destacando que maiores vínculos sociais e sociabilidades mais plenas tendem a reforçar tal possibilidade.

\section{Direito à cidade}

Assim como as condições econômicas, e como reflexo destas, as condições de uso e apropriação dos espaços são muito desiguais entre os possíveis usuários e fruidores das cidades. Tanto as opressões econômicas quanto outras opressões negam recorrentemente nosso direito à cidade. As interseccionalidades se impõem sobre muitos de nossos direitos. Quem frequenta e quem não frequenta os espaços mais formais da cultura? Quem se apropria e quem não se apropria dos diversos espaços das cidades? Tanto algumas práticas culturais quanto alguns territórios não negados a alguns sujeitos, e fica evidente a reduzida mobilidade e apropriação na/da cidade gerada por questões de gênero, de condição econômica, de raça etc. 
O território não é neutro, tendo seus usos permitidos, estimulados, proibidos. Vive-se forte disputa e conflito entre a dominação do espaço pelo Capital e pelo Estado (normalmente atuando em parceria) e a apropriação do mesmo pelos usuários.

A definição de território apresentada por Barbosa (2017, p. 13) mostra-se oportuna para aclarar o entendimento que queremos corroborar:
Afigura-se um conceito de território como um conjunto complexo e indissociável de práticas sociais - econômicas, políticas, culturais, ideológicas - que se revela como escrita temporal de sujeitos e como impressão espacial de ações, técnicas e objetos no chão de nossas existências. É assim que as contradições, os conflitos e as disputas sobre os rumos de uma sociedade ganham visibilidade e praticidade. E, é claro, onde as relações de solidariedade, amizade e confiança também marcam sua insistente presença para renovar o presente e inventar outro futuro.

Acontece que, e seguindo a perspectiva da produção capitalista do espaço, na maioria das vezes os espaços são produzidos com ênfase em seu valor de troca; queremos aqui evidenciar que os territórios sejam produzidos sob outra lógica que não a do mercado: produção do espaço por seu valor de uso - sobre este tema, pode indicar os textos de Rodrigues (2015a; 2015b).

A arquiteta urbanista iraniana Faranak Miraftab (2004; 2016) propõe duas terminologias, designando por espaços convidados aqueles sob controle e produção por parte do Estado e grupos hegemônicos, e espaços inventados aqueles produzidos pela informalidade dos grupos sociais que se apropriam dos espaços, mas que são muitas das vezes "criminalizados".

Miraftab (2004, p. 1, tradução minha) assim apresenta: "Espaços 'Convidados' são definidos como aqueles ocupados por grupos sociais e suas organizações nãogovernamentais aliadas que são legitimadas pelo governo. Espaços 'Inventados' são aqueles, também ocupados por bases sociais e suas ações coletivas, mas que confrontam diretamente as autoridades e o status quo".
Em publicação mais recente, a autora reforça sua proposição sobre a insurgência dos espaços inventados:

O planejamento insurgente avança
essa tradição ao abrir a teorização do
planejamento a outras formas de ação,
para incluir não apenas formas
selecionadas de ação dos cidadãos e
de suas organizações sancionadas
pelos grupos dominantes, as quais
designo de espaços de ação
convidados; mas também as
insurreições e insurgências que o
Estado e as corporações
sistematicamente buscam colocar no
ostracismo e criminalizar - que
designo de espaços de ação
inventados. [...] Os dois tipos de
espaços que discuto encontram-se em
uma relação dialética e de interação
mutuamente constituída, não em uma
relação binária. Evidências concretas
mostram que as práticas dos
movimentos sociais, que almejam
alcançar mais do que as necessidades
individuais, que é a meta da inclusão
liberal, frequentemente tem de se
mover através e entre aqueles espaços
de acordo com as necessidades
específicas da luta. Mas instituições de
poder, tais como a mídia dominante, o
Estado, organizações internacionais
de ajuda, configuram esses espaços
convidados e inventados em uma
relação binária, e tendem a
criminalizar os últimos, designando
apenas os primeiros como espaços
“apropriados” para as vozes e
participação dos cidadãos. (Miraftab,
2016, p. 368-369)

Constatamos a crueldade (às vezes ostensivamente, às vezes sob a tônica da ideologia no plano do imaginário) que Estado e Capital fazem para inibir a livre produção espacial e o pleno direito à cidade, sua produção e apropriação.

Alguns exemplos observados em pesquisas ajudam na ilustração. Praças públicas de nossas cidades vêm sendo palco de rodas culturais (com batalhas de rima e demais expressões da cultura hip hop), manifestações que costumam dotar esses espaços públicos de maior vitalidade e laços de coesão social e afetividade. Muitas das vezes tais práticas artístico-culturais são criminalizadas e os 
jovens delas praticantes são coagidos, constrangidos e/ou alijados, geralmente por aparatos policiais. Entender formas novas e mesmo recorrentes de apropriação dos territórios coletivos e sua potência em termos de sociabilidade pode promover e reforçar a disputa por políticas urbanas e culturais mais inclusivas e socialmente justas (ver Rodrigues \& Correia, 2017). Pudemos observar relações hostis em várias Rodas Culturais, com forte rejeição e preconceito aos jovens delas participantes, com expressões do tipo "são marginais esses jovens que ficam cantando aqui na praça; falam palavrões e usam argumentos bem impróprios"; "a única coisa boa que acontece nos dias desses eventos é que a polícia vem vigiar o que estes jovens estão fazendo". Raros são os casos nos quais comerciantes e moradores dos entornos de praças com tais atividades interagem com os participantes das Batalhas de Rima4. Estes exemplos ilustram a criminalização dos denominados por Miraftab (2004) como espaços inventados.

Outro exemplo, fruto de pesquisas pessoais, que merece destaque são determinadas práticas juvenis que acontecem no Caminho Niemeyer no centro da cidade de Niterói/RJ: exemplifica a criminalização de determinadas práticas sob alegações que vão desde "andar de skate e patins aqui devia ser proibido; suja e pode estragar a bela arquitetura de Oscar Niemeyer" até "os jovens vêm pra cá para beijar na boca, beber vinho e fumar maconha..."

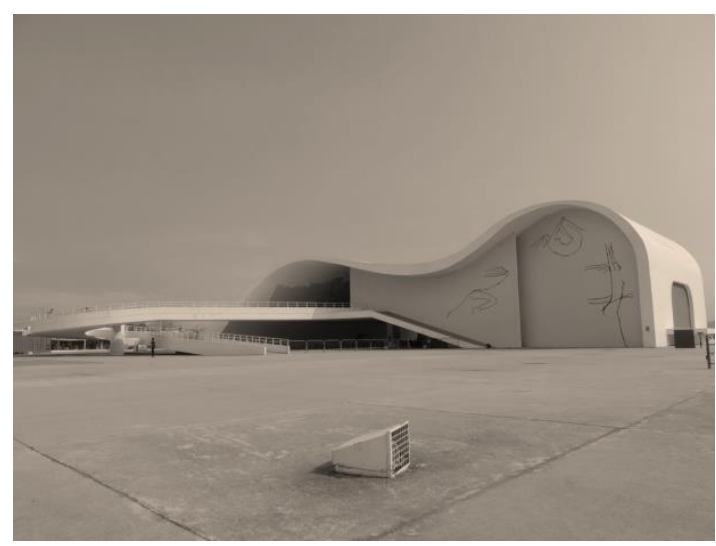

Figura 4. Trecho do Caminho Niemeyer em Niterói/RJ no qual se vê o Teatro Popular Oscar Niemeyer e as superfícies em plaqueado de cimento para os quais muitos jovens se dirigem após a saída do colégio (fonte: autor, 2018).

A figura seguinte (Figura 5) é muito emblemática sobre como os espaços são "pensados" de modo falacioso. A imagem mostra outro trecho do Caminho Niemeyer, no Centro de Niterói. O local é visitado sobretudo por turistas que querem apreciar as obras desse famoso arquiteto. Os moradores da cidade por vezes pouco conhecem o lugar, mesmo aqueles que moram no Centro.

Muitos jovens têm se dirigido para esse local após as aulas, mas muitas vezes têm sido impedidos de entrar - o local é todo gradeado - sob alegações de que há pouco policiamento para efetivo controle do espaço [sic]. A situação se altera quando são previstos eventos, acentuando a negação de que esse espaço seja um lugar público de uso corrente na cidade. Na Figura 5 podemos ver um castelo de areia erguido em novembro de 2014 com o objetivo de ser a maior realização do tipo e entrar para o livro dos Records (o que de fato se deu). Pois bem, o fato poderia ter sido um bom atrativo de pessoas para o Caminho Niemeyer, espaço normalmente com pouco uso; qual nada, após os registros fotográficos, o Castelo de Areia foi demolido.

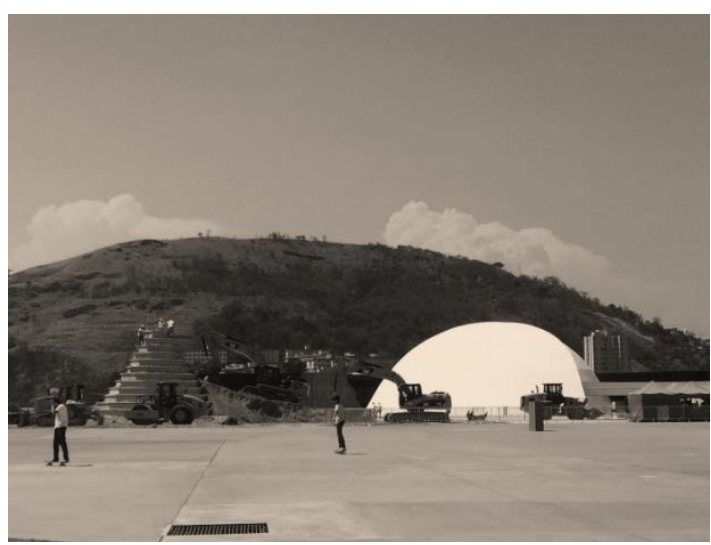

Figura 5. Trecho do Caminho Niemeyer no qual se vê, à esquerda, a construção do recordista Castelo de Areia erguido em novembro de 2014 (fonte: autor).

Seguimos presenciando a cultura ser tratada muitas das vezes - como espetáculo; também a cena urbana não privilegiando que possamos ser protagonistas ao invés de meros coadjuvantes. Quero que o espetáculo de nossas vidas possa ser inspirado em Bertolt Brecht, que defendia que os expectadores tivessem plena consciência sobre a encenação, num movimento contrário à catarse no teatro grego e à passividade do palco italiano. A referência a Brecht me parece adequada para defender como deve se configurar o espetáculo das cidades, a apropriação efetiva dos espaços urbanos 
coletivos. Brecht refletiu sobre a situação dos anos 1940, 1950. A tônica da urbanística modernista, desejada sobretudo a partir dos anos 1930, ganhou fortes críticas nos idos dos anos 1960, sob a alegação que a setorização e o excessivo planejamento dos espaços das cidades geravam distanciamento entre os usuários e enfraquecimento de suas possibilidades de efetiva apropriação. Tal pensamento teve pouca aderência em muitas partes do mundo e pode-se dizer que nenhum impacto aqui no Brasil (basta lembrar que estávamos, naquele momento, construindo Brasília - exemplo maior do urbanismo modernista [para maiores reflexões sobre o tema, sugiro em especial os capítulos 6 e 8 de Rodrigues (2001). Minha argumentação vai na direção de reafirmar que muito pouco se avançou na perspectiva de se retomar os espaços coletivos das cidades para real uso e apropriação dos mesmos, reforçando elos de coesão social entre os sujeitos. A tônica do planejamento estratégico cada vez mais em sintonia com a lógica do capital, buscando a melhor forma de "vender" as cidades para a especulação financeira e turística de forte atratividade e fraca apropriação. Práticas culturais e vida urbana ficam, ambas, sob as luzes da espetacularização. Se precisamos desculturalizar a cultura como defendeu Victor Vich, eu diria que precisamos também desplanejar o planejamento urbano.

Parto do pressuposto de que o espaço urbano pleno é aquele que possibilita uma apropriação múltipla que o consolide enquanto "lugar", nas acepções de Certeau (1998), que aponta que lugar é espaço praticado, pois ligado às pessoas, e Augé (1994), que cunha a expressão não-lugar para designar espaços marcados pela efemeridade, por apropriações rarefeitas e momentâneas. Lucrecia Ferrara (1999) chama de turismo dos deslocamentos virtuais a forma como os visitantes tendem a se relacionar com o espaço: de modo efêmero e superficial, atentando-se a recortes imagéticos que pouco ou nada traduzem do lugar em si, e que são efeitos perversos da contemporaneidade.

Constatei- como já apontado - que a produção do espaço universitário no Brasil ao longo do século XX seguiu a idealização e consolidação de um modelo urbanístico único, com possibilidades mínimas de ruptura (ao menos até fins do século, mas provalvemente até hoje). Em complemento, constato, ainda hoje, espaços privilegiados de várias cidades serem tratados também de maneira idealizada que mais valoriza sua carga sígnica do que suas possibilidades de apropriação. Ou seja, há uma tensão entre as possibilidades de mudança e diversidade e a cristalização de valores que as emperram. Outros exemplos ilutrativos podem ser trazidos, mantendo-se a implantação de outras obras de Oscar Niemeyer em Niterói.

O Museu de Arte Contemporânea (MAC) foi implantado num platô que era um mirante onde se reuniam os jovens após as "baladas" noturnas (por conta de trailer que vendiam hamburgeres e similares). Sua construção data de 1996 e foi o primeiro projeto de Niemeyer na cidade. Logo se tornou importante ícone, como atestam as manchetes do jornal O Globo à época: " O cálice está quase pronto para a festa" (28/07/96); "MAC transforma Niterói em pólo turístico" (09/03/97); "Uma cidade com a grife Oscar Niemeyer" (04/05/97).

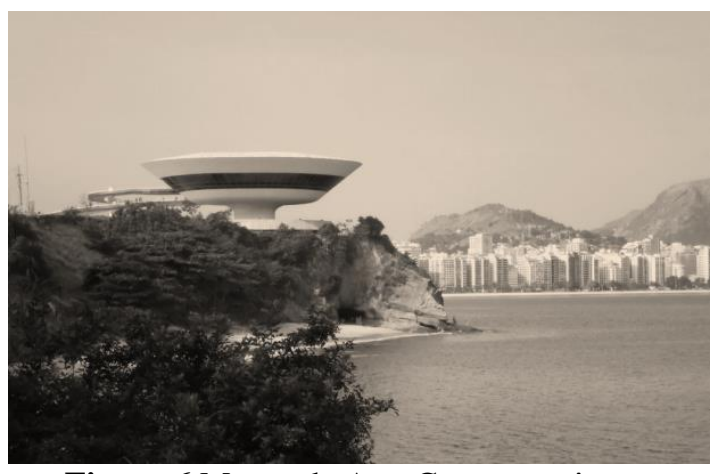

Figura 6.Museu de Arte Contemporânea, implantado no mirante da Boa Viagem (Niterói/RJ) (fonte: autor).

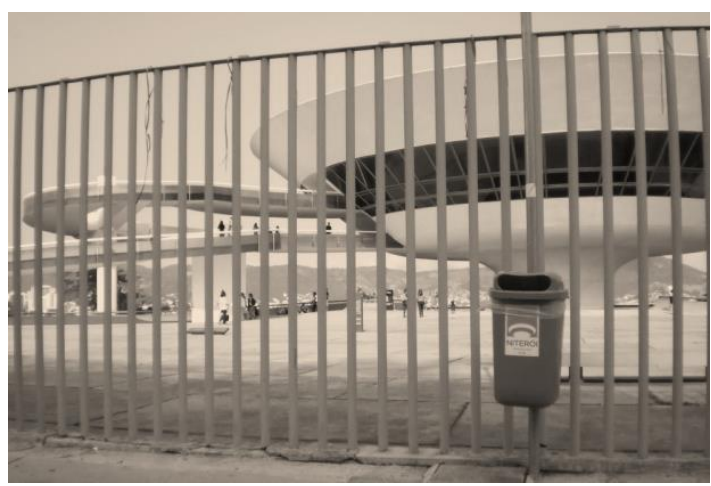

Figura 7. O MAC, devidamente "resguardado" pelas grades (fonte: autor).

O mirante onde se reuniam e se encontravam constantemente vários moradores cedeu lugar ao principal ícone da cidade, que mesmo com suas generosas áreas externas é vedado à livre circulação (atualmente as grades foram 
substituídas por vidros para melhor visualização da obra arquitetônica).

A gentrificação é outro resultado desse modelo urbanístico que pouco favorece à apropriação e uso do espaço pelos cidadãos como um todo 5 .

\section{Crítica racional $X$ crise de paradigmas}

A modernidade, nesses tempos de globalização, transforma os preceitos fundamentais da História, e de forma paradoxal. Transforma o tempo em falta de tempo e, por outro lado, altera as relações temporais. Transforma o espaço em falta de espaço e, por outro, cria relações transespaciais. Cria a perplexidade do novo, que a um só tempo apóia-se e descarta a tradição. Nas palavras de Boaventura Santos (1996, p. 21 e 22),

assiste-se a um desabrochar de novas identidades regionais e locais alicerçadas numa revalorização do direito às raízes [...]. Este localismo (...) é com freqüência adotado por grupos deindivíduos 'translocalizados'(...)”; "o indivíduo parece hoje menos individual do que nunca"... "a sua liberdade de escolha nunca foi tão derivada dasescolhas feitas por outros antes dele.

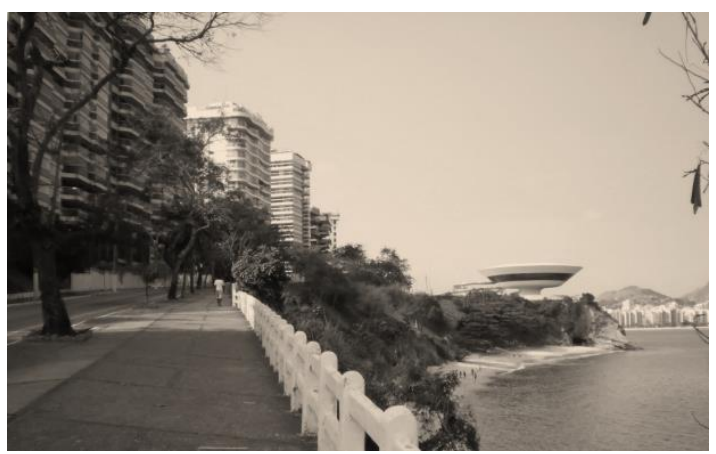

Figura 8. O MAC e seus entornos gentrificados (fonte: autor).

É interessante a observação desse autor, em relação à crise paradigmática da modernidade contemporânea, ao associar o seu esgotamento, com a "redução das possibilidades da modernidade, às possibilidades do capitalismo". (Santos, 1996, p. 34)

A arquitetura não pode correr à margem do sistema, uma vez que ela precisa do Capital (e do Estado) para concretizar-se. Outras produções culturais (literatura, pintura etc.) têm, sob este aspecto,maior independência. A busca da arquitetura moderna foi, utopicamente, a de nãosignificar nada além do que sua forma/função, no entanto uma carga simbólica sempre haverá, e as pessoas fatalmente lhe darão outros significados. Estes, ao invés de aproximar as pessoas, as afastam dos espaços assim constituídos.

Críticas ao moderno que ganham vulto da década de 1970 não são absorvidas. Um dos símbolos dessa crítica pós-moderna, um símbolo de ruptura com o modernismo, pode ser associado à implosão do projeto habitacional Pruitt-Igoe, em St. Louis, Missouri (EUA), dinamitado em 15/07/72, após várias tentativas de recuperá-lo das destruições promovidas por seus usuários (Connor, 1993).

No Brasil, a metaforização do "arquiteto" como um"não comummortal", talvez seja uma pista, em relação às resistências à ruptura com um modelo universal e segregador. A arquitetura moderna no Brasil, desde a década de 1930, foi tendo muita ênfase, tornando-se algo importante nacionalmente, e com ela a expressividade desse seu responsável, ou seja, o arquiteto. A coisa foi só crescendo: Pampulha e Brasília, no cume. Não apenas Niemeyer e Lúcio Costa são postos em cena; de certa forma eles puxam os demais. Eles são como metonímias do arquiteto, e mais do que isso, da arquitetura modernista. Então, num país em que este símbolo está tão impregnado em nossa fantasia, fica difícil romper com ele.

Na implantação do modernismo na arquitetura e nourbanismo, noBrasil, as universidades acabaram tendo um peso forte, até por conta da associação que foi feita por parte de governos autoritários (em especial a Era Vargas e a Ditadura Militar), que queriam legitimar-se a partir desses preceitos: ligados à modernidade através desse forte viés -aarquitetura moderna-, e fazendo da educação um dos caminhos de naturalização dessa imagem.

Poderíamos ter vislumbrado para a Universidade também o papel de "revisora desse modelo homogêneo", mas não foi o que aconteceu. As tentativas de ruptura buscadas por algumas universidades, ao menos em relação ao seu espaço físico interno, tiveram pouco eco. O quadro contemporâneo é - ao que nos parece - cada vez mais acirrado: a cidade aparta-se cada 
vez mais, segrega-se internamente cada vez mais; condomínios gradeados, dicotomia cidade/morro, áreas de interesse turístico cooptadas/direcionadas aos interesses prioritários do capital, planejamento territorial entendido sob lógicas do planejamento estratégico de grandes intervenções etc. O símbolo da racionalidade da modernidade ficou impregnado em nós.

Adorno e Horkheimer (1985), em sua Dialética do Esclarecimento, já nos apontavam, em meados do século passado, a falácia do projeto racionalista, pois o próprio conceito de razão que conforma a cultura converte civilidade em barbárie. A gênese da subjetividade é construída a partir da fantasia do poder sobre a natureza e sobre o indivíduo. O totalitarismo da modernidade espelha-se numa lógica de uniformização a degradar o próprio homem a mero objeto da natureza. Cabe, porém, destacar que esse sempre-o-mesmo apresenta-se disfarçado em novidade (a lógica capitalista).

Vivemos um reiterado processo de retomada de ideais iluministas que produzem uniformizações (travestidas de diversidade, cabe reiterar). É preciso "remar contra a correnteza", isto é "varrer a história a contrapêlo" e buscar soluções que melhor vivifiquem nossos espaços de convívio, seja na cidade como um todo seja em alguns de seus recortes. Preconizamos (neste artigo e em outros escritos) a necessidade de se mesclar métodos que tragam aportes culturais à produção urbana, de modo a melhor entender certos impasses que nos envolvem e vislumbrar alternativas. Metodologias e reflexões que possam aclarar (ou se aproximar de possíveis razões) inibições e expectativas de recepção e uso de espaços urbanos, contribuindo mais incisivamente com nossos direitos à cidade (e a produzi-la na perspectiva de que somos todos capazes de produzir políticas) e com nossos direitos à cultura, entendida aqui em dimensões amplas que ultrapassam o campo estrito da Arte e a colocam inserida em nossas práticas como um todo, com foco nas interações sociais permitidas/estimuladas pelo uso do espaços público.

\section{Notas}

${ }^{1}$ Marco da arquitetura moderna no Brasil, o edifício do Ministério da Educação e Saúde (atual Palácio Gustavo Capanema), no Rio de Janeiro, é o resultado do trabalho de um grupo arquitetos liderados por Lucio Costa, e do qual participaram diversos arquitetos de vertente modernista, entre eles Oscar Niemeyer, tendo tido consultoria de Le Corbusier. A construção do edifício, iniciada em 1937, conhece um primeiro acabamento exterior em 1942, mas só é inaugurada oficialmente em 1945, por Getúlio Vargas.

${ }^{2}$ O presidente Getúlio Vargas foi eleito em 1930, tendo ficado do cargo até 1945, após golpe de Estado em 1937.

${ }^{3}$ UB - Universidade do Brasil; UFRJ Universidade Federal do Rio de Janeiro; USP Universidade de São Paulo; UFMG Universidade Federal de Minas Gerais

${ }^{4}$ Exemplo contrário, importante de se citar aqui, é o da Batalha do Tanque, na Praça dos ExCombatentes em São Gonçalo/RJ no qual participantes desta Batalha e alguns comerciantes do entorno interagem de modo pleno; maiores exemplificações e reflexões sobre essa temática podem ser encontradas em Correia, 2019.

${ }^{5}$ Maiores detalhamentos sobre resultados econômicos, simbólicos e sociais provocados pelas implantações de obras assinadas por Oscar Niemeyer na cidade de Niterói se encontram em Rodrigues (2015a).

em: http://dx.doi.org/10.9771/1983-3717pcr. v2i2.4268 [Acesso em 10 Janeiro 2019]:

Barbosa, J. L. (2017). Cultura e Território. Rio de Janeiro, Lumen Juris.

Benjamin, W. (2012). Magia e técnica, arte e política: ensaios sobre literatura e história da cultura. São Paulo, Brasiliense.

Castro, F. L. \& Rodrigues, L. A. F. (2017). Cultura e Gestão Cultural. Rio de Janeiro, Lumen Juris. 
Certeau, M. de (1998). A invenção do cotidiano. Vol. 1: Artes de fazer. Petrópolis, Vozes.

Connor, S. (1993). Cultura Pós-Moderna: introdução às teorias do contemporâneo. São Paulo, Edições Loyola.

Correia, M. S. (2019). A rima é das minas, dos manos, dos gays? Um estudo sobre rodas de rimas e suas representações sociais em Itaipuaçu/Inoã e Itaipu. Niterói/RJ: Universidade Federal Fluminense [dissertação de mestrado em Cultura e Territorialidades].

Duxbury, N., Garret-Petts, W. F. \& Maclennan, D. (eds.) (2015). Cultural Mapping as Cultural Inquiry. New York, Routledge.

Duxbury, N., Moniz, G. C. \& Sgueo, G. (eds.) (2013). Rethinking Urban Inclusion: Spaces, Mobilizations, Intervention. CesContexto, Centro de Estudos Sociais, Universidade de Coimbra, Debates, $\mathrm{n}^{\mathrm{o}}$ 2, junho. Disponível em: https://www.ces.uc.pt/publicacoes/cescontexto/fic heiros/cescontexto_debates_ii.pdf. [Acesso em 22 Abril 2019].

Ferrara, L. d'A. (1999). O turismo dos deslocamentos virtuais. In: Yázigi, E., Carlos, Ana Fani e Cruz, R. C. (orgs.). Turismo: espaço, paisagem e cultura. São Paulo, Hucitec, pp. 1524.

Fraser, N. (2006). Da redistribuição ao reconhecimento? Dilemas da justiça numa era "pós-socialista". Cadernos de campo, São Paulo, n. 14/15, pp. 231-239. Disponível em: http://www.revistas.usp.br/cadernosdecampo/artic le/view/50109/54229. Última consulta em: $10 \mathrm{de}$ janeiro de 2019. DOI: https://doi.org/ 10.11606/issn.2316-9133.v15i14-15p231-239

García Canclini, N. (ed.) (1990). Politicas culturales en América Latina. México/D.F., Editorial Grijalbo.

Jacobs, J. (1977). The death and the life of great American cities: the failure of town planning. London: Pelican Books.

Lemos, C. A. C. (1979). Arquitetura Brasileira. São Paulo, Melhoramentos/EdUSP.

Miraftab, F. (2016). Insurgência, planejamento e a perspectiva de um urbanismo humano. Revista Brasileira de Estudos Urbanos e Regionais, Recife, v.18, n.3, 363-377. Disponível em: https://doi.org/10.22296/2317-1529.2016v18n3 p363.

Miraftab, F. (2004). Invited and Invented Spaces of Participation: Neoliberal Citizenship and feminists' Expanded Notion of Politics. Wagadu, v. 1, spring, pp. 1-7. Disponível em: http://www.rrojasdatabank.info/neolibstate/miraft ab.pdf. [Acesso em 10 Janeiro 2019].
Qadeer, M. A. \& Agrawal, S. K. (2011). The Practice of Multicultural Planning in American and Canadian Cities. Canadian Journal of Urban Research, 20, $\mathrm{n}^{\mathrm{o}} 1$ (Supplement 2011), 132-156.

Rodrigues, L. A. F. (2001) Universidade e a fantasia moderna; a falácia de um modelo espacial único. Niterói, EdUFF.

Rodrigues, L. A. F. (2009) Gestão cultural e seus eixos temáticos. In: Curvello, M. A. et al (orgs.). Políticas públicas de cultura do Estado do Rio de Janeiro: 2007-2008. Rio de Janeiro, Uerj/Decult, pp. 76-93.

Rodrigues, L. A. F. (2012) Gestão cultural e diversidade: um ponto de cultura em estudo. In: Frade, Cáscia [et al] (orgs.). Políticas públicas de cultura do Estado do Rio de Janeiro: 2009. Rio de Janeiro, Uerj/Decult, pp. 143-158.

Rodrigues, L. A. F. (2015a). Cultura, território e economia - estudos do caminho Niemeyer em Niterói/RJ. In: Castro, F. L.; Telles, M. P. Dimensões econômicas da cultura: experiências no campo da economia criativa no Rio de Janeiro. Rio de Janeiro, Lumen Juris, pp. 113-160.

Rodrigues, L. A. F. (2015b) Identidad cultural y desarrollo urbano: ¿proyectos engañosos? PragMatizes - Revista Latino-Americana de Estudos em Cultura. Niterói, RJ, Ano 5, número 9, abr-set., pp. 25-36. Disponível em: http://periodicos.uff.br/pragmatizes/article/view/1 0409/7248. [Acesso em 10 Janeiro 2019].

Rodrigues, L. A. F., Correia, M. (2017). Política cultural e território: potência e inibição das sociabilidades. In: Calabre, Lia [et al.] (orgs.) Anais do VIII Seminário Internacional Políticas Culturais. Rio de Janeiro, Fundação Casa de Rui Barbosa.

Sandercock, L. (2005). Debatendo o preconceito: a importância das histórias e de sua narração na prática do planejamento. Cadernos IPPUR, Rio de Janeiro, Ano XIX, 289-315.

Santos, B. de S. (1996). Pela mão de Alice: o social e o político na pós-modernidade. São Paulo, Cortez.

Santos, C. N. F. dos (1988). A cidade como um jogo de cartas. Niterói, São Paulo, EdUFF/ Projeto.

Vich, V. (2015). Desculturalizar a cultura: Desafios atuais das políticas culturais. PragMatizes - Revista Latino-Americana de Estudos em Cultura, Ano 5, número 8, out/2014 a mar/ 2015, 11-21. Disponível em: http://periodicos.uff.br/pragmatizes/article/view/1 0398/7237. [Acesso em 10 Janeiro 2019]. 


\section{Tradução do título, resumo e palavras-chave}

Morphological shocks and crises of sociability in university space and in the urban space

Abstract. The present text discusses the permanence of some morphological models implanted in Brazil since shortly before the middle of the 20th century until today, arguing that it privileged formal aspects instead of social relationsin the territories. Based upon studies on the production of University spaces, stating that the production of certain urban spaces in contemporary cities - particularly those treated under the logic of the tourist attractiveness, but not only-reinforce fallacious ideas, such as the first. In this way, are created distinct morphologies that present little dialogue: ruptures in the morphological relations between University space and urban space, and ruptures within the urban fabric in general. The text is based on arguments that claim to reinforce urban qualities based on the possibilities of strengthening sociability, pondering that such precepts are minimized by logics that privilege the imaginary load of spaces in detriment of other social and cultural values.

Keywords. university space, contemporary urban space, sociabilities, urban cultural planning.

Editor responsável pela submissão: Renato Saboya.

Licenciado sob uma licença Creative Commons.

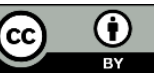

